two new elements in them, niobium and pelopium. The latter supposed element was afterwards found to be non-existent, but the niobium was merely the old columbium under a new name. That name in some mysterious manner was substituted by the German chemists for the original appropriate name, and has been in general use in Europe ever since. In America the name columbium has been generally preferred, and was formally endorsed by the Chemical Section of the American Association for the Advancement of Science more than twenty years ago. In England, also, columbium is much used, as, for example, in Roscoe and Schorlemmer's "Treatise on Chemistry," Thorpe's "Dictionary of Applied Chemistry," and the new edition of the "Encyclopædia Britannica."

The foundation of Rose's error seems to have been an uncritical acceptance of Wollaston's views; for he speaks of all the minerals he studied as tantalite. $\mathrm{He}$ also, at least in his original memoir, claims that the atomic weight of niobium is greater than that of tantalum, and here he was obviously wrong.

In shurt, the name columbium has more than forty years" priority, and during that interval was accepted by many chemists, and was more or less in current use. To employ the name niobium is not only unhistorical, but it is also unfair to the original discoverer, meaningless, and without any justification whatever. Furthermore, it injures the splendid reputation of Rose, for it perpetuates and emphasises one of his few errors. The recommendation of the committee above-mentioned should not be accepted, for it is opposed to the established rules of priority.

F. W. Cllarke.

\section{A New Etching Reagent for Steel.}

What I believe to be a novel and useful reagent for the etching of steel specimens for microscopic examination has recently been worked out in this laboratory by the writer, in conjunction with Mr. J. L. Haughton. A very brief account in this place is perhaps justified in view of the fact that the opportunity for publishing a full account of the work in the usual way will not occur for some months.

The etching reagent consists of an acid solution of ferric chloride, similar to that frequently used for etching copper alloys, but containing about $0 \cdot I$ per cent. of cupric chloride and about half that quantity of stannic chloride. The copper in this solution is, of course, displaced by the iron of any steel specimen exposed to it, and the copper is deposited on the surface of the steel. We have, however, discovered that in ordinary carbon steels this action can be made to occur in such a way that a thin deposit of copper is slowly formed on the ferrite, while pearlite and cementite are only very slightly affected. Under the microscope the ferrite appears to be blackened, while the pearlite remains bright. The appearance of the etched specimens is thus the exact negative of that obtained by ordinary reagents, provided that the steel is very pure. We have found, however, that in commercial steels the ferrite is not darkened uniformly, but that a strongly banded structure is developed. Apparently the rate of deposition of copper is greater the purer the ferrite, one of the most important impurities in this regard being phosphorus. By a suitable use of the reagent, patterns are obtained which indicate the distribution of the phosphorus in a clear and striking manner and it is thus possible to obtain in two minutes by the use of the new reagent results hitherto only obtainable by the process of "Teat tinting."

By the kindness of Dr. J. E. Stead, F.R.S., we have been enabled to compare the patterns obtained by heat-tinting on one of Dr Stead's own specimens and those obtained by means of our reagent on the same surface after repolishing, and these patterns have proved identical. Beyond this, however, the new method of etching by the electro-chemical deposition of another metal promises to open up many possibilities in the study of the structure of metals, but these we have not yet had time to work out.

The National Physical Laboratory, Walter Rosenhain.

December 3I, I9I3. (Wernher Metallurgy Laboratory),

\section{Dr. J. F. Thorpe's " Caged" Compound.}

As Dr. J. F. Thorpe has apparently found difficulty in representing his newly discovered tricarboxylic acid by a formula in the plane of the paper (vide Proc. Chem. Soc., vol. xxvii., p. 347), may I suggest

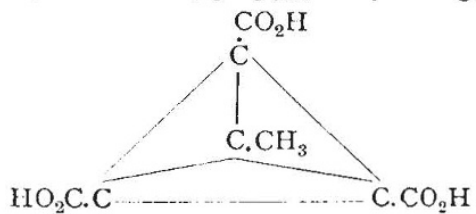

as being as good as the one he suggested if not preferable to it.

A "caged" cube compound, $\mathrm{C}_{8} \mathrm{X}_{8}$, could similarly be advantageously represented by the projection formula :-<smiles></smiles>

W. W. REED.

Technical Institute, Norwich,

December 16, 1913.

Mr. ReED is quite right, and doubtless the formula he suggests will have to be adopted for this and similar compounds when it is desired to express their structure graphically on the plane of the paper.

It is, however, evident, as Prof. Armstrong stated at the meeting of the Chemical Society, that a large number of organic compounds are very inadequately represented by the usual two dimensional formulæ, and that it will be necessary, in the near future, to reconsider our method of portraying the structure of these substances. The isolation of the compound under discussion, for which, on Prof. Armstrong's suggestion, the name methyl-tetrahedrene tricarboxylic acid has been adopted, merely serves to accentuate the limitations of our present method, for it is evident that the formula suggested by Mr. Reed does not represent the true relative positions of the carbon atoms in the molecule. For example, it is difficult to understand that the formula

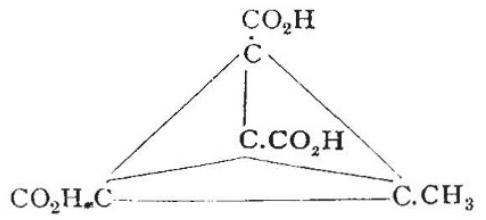

represents the same compound as Mr. Reed's formula.

This is still more apparent in Mr. Reed's cube formula, in which it is difficult to realise that the eight carbon atoms are of equal value.

J. F. T.

NO. 2306 , VOL. 92$]$ 